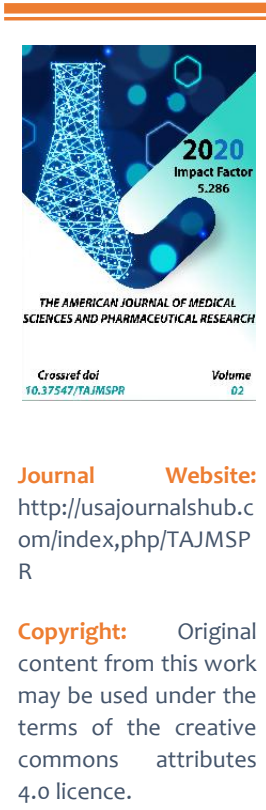

\title{
False Anerism Of Connective Artery After Fracture
}

\author{
Zayniddin Norman ugli \\ “The Republican Specialized Center For Surgery Named After Academician V.Vakhidova \\ "Republic Of Uzbekistan, Tashkent.
}

\section{ABSTRACT}

In the clinic RSCH them. Acad. V. Vakhidov was hospitalized for 73 years after a trauma to the right supraclavicular region. In after the injury the patient had pain; feeling of pressure in the supraclavicular region; numbness of the right upper limb; lack of movement of the fingers of the right cyst and general weakness. The patient underwent MSCT angiography-occlusion of the right subclavian vein. Stenosis of the right subclavian artery. A CT scan is a sign of a mass of the formation of the right over the subclavian region with the dissection in the right axillary region. At the first stage, under intubation anesthesia, endovascular occlusion of the subclavian artery was performed.

At the first stage, under intubation anesthesia, endovascular occlusion of the subclavian artery was performed. Then surgery was performed: the elimination of the subclavian artery aneurysm, on the right with the removal of hematoma. The presented clinical observation demonstrates a rare case of a false aneurysm of the subclavian artery with hematoma formation after a clavicle fracture.

\section{KEYWORDS}

False aneurysm, subclavian artery, clavicle fractures, reconstructive operations. 


\section{INTRODUCTION}

Surgical treatment of traumatic arterial aneurysm is an urgent problem in vascular surgery $[1,2,3,6]$.

Surgical treatment of vascular injuries and their consequences has a 2000-year history. Despite this, some issues remain insufficiently resolved and require their further development [5]. Until the beginning of the 2oth century, surgical interventions for traumatic vascular injuries and their consequences were mainly palliative in nature [4].

Damage to the main arteries is a severe injury due to the high frequency of local and general complications occurring in $15.4-48.4 \%$ of cases. Subclavian artery trauma, a rather rare form, accounts for about $2 \%[6,8]$. With puncture, stab-cut wounds with a narrow wound channel, closed blood clots and injuries of the subclavian artery, they can lead to traumatic aneurysms or traumatic atherovenous fistulas [10].
At the same time, vascular ligation was the main method used to stop bleeding and save the victim's life, which led to a large percentage of amputations [9].

Here is a clinical observation.

Under local anesthesia, $6 \mathrm{~F}$ introducer sheaths were inserted into the femoral arteries on both sides. At the same time, an rentgenendovascular temporary complete balloon occlusion of arterial vessels was performed. In this case, a balloon catheter with dimensions of $6 \times 60 \mathrm{~mm}$ was used; for expansion to complete occlusion and vascular patency. The occlusion occurred at a pressure in the balloon up to $9 \mathrm{~atm}$ with an RBP of 10 atm. Contrast Unigexol-350 - $100 \mathrm{ml}$ (1 bottle of $100 \mathrm{ml}$ ). At the same time, 3 thousand MED heparin was introduced (Fig. 1).

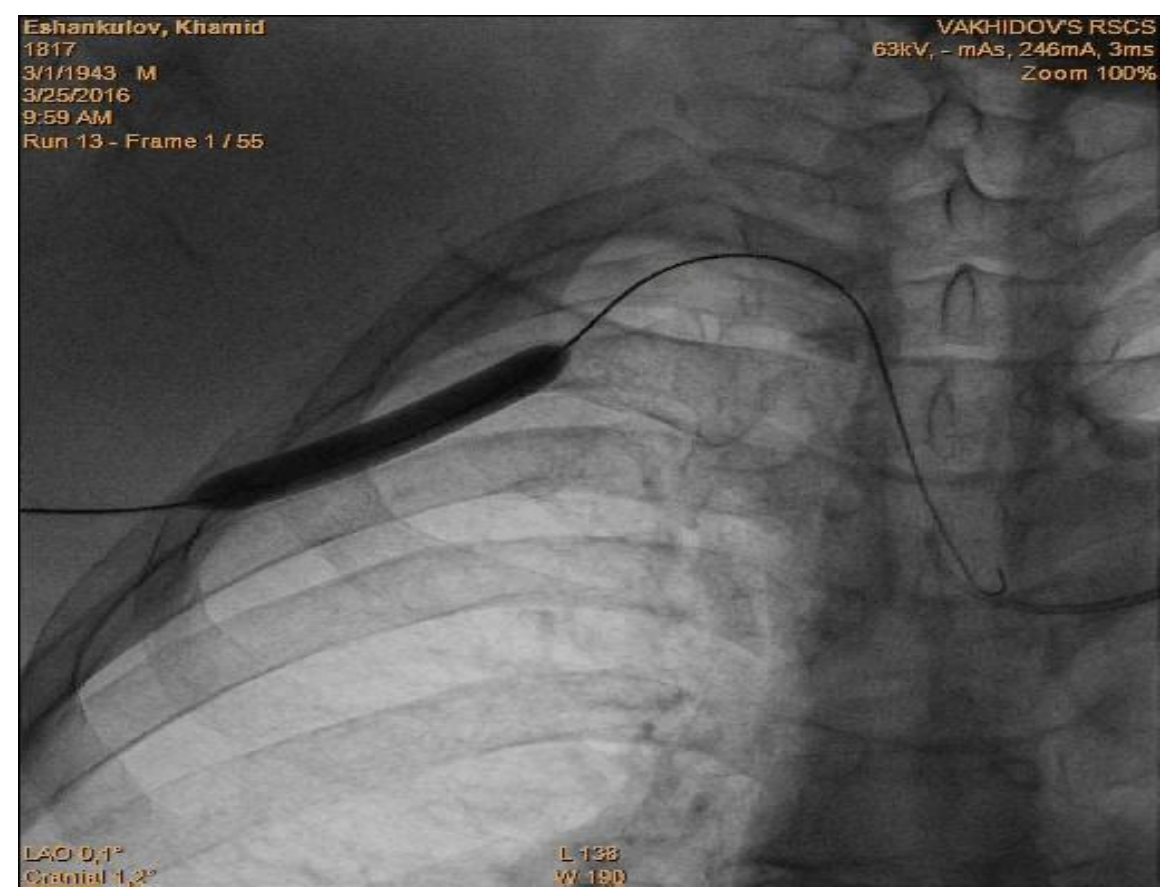

Fig. 1. Rentgenendovascular complete occlusion of the right subclavian artery. 
The patient, 73 years old, was admitted to the clinic of the RSTSH them. Acad. Vakhidov in a planned manner for a traumatic aneurysm in the subclavian artery, on the right. Considers himself ill during the last 4 months, when complaints of pressure and pain in the supraclavicular region have appeared; the presence of education on the supraclavicular region on the right; numbness of the right upper limb; lack of movement of the fingers of the right cyst, general weakness.

The patient was treated by traumatologists. The last 20 days before contacting us, the above indication of the complaint appeared.

On examination it was established: the general condition upon admission is satisfactory; normal physique; skin of normal color; peripheral lymph nodes are not enlarged; vesicular breathing in the lungs, on both sides; percussion over the lungs pulmonary sound; muffled heart sounds; Heart rate 80 beats per minute. BP 120/80 $\mathrm{mm}$. t. Art; the stomach of the usual form, participates in the act of breathing; On palpation, the abdomen is soft, painful; the liver and spleen are not enlarged. Beating symptom negative on both sides; physiological functions are not disturbed.

On examination, the upper and lower limbs are of the same perimeter. No edema. Ripple at all recognition points is determined. In the supraclavicular region, on the right, there is a pulsating formation - $10 \times 12 \mathrm{~cm}$ in size motionless; painless, the skin over it is not changed. In the right lower extremity, the activity of the cyst movement of the fingers of the cyst is absent and the sensitivity is reduced. On auscultation, a systolic murmur is heard over the formation (Fig. 2).

Examination: Complete blood count: HB-113g / I. Erythrocytes - 3,8x1012/l; leukocytes -5,7x109 / I. General urine analysis - protein-0.099, epit.units / pr. lei.ed / pr. Biochemical blood test: Sugar-6.8. ECG: sinus rhythm. Heart rate 90; EOS horizontal position; Dystrophic manifestations in the myocardium.

Fluoroscopy: Pulmonary fields, without fresh focal infiltrative shadows. The roots of the lungs are heavy. The domes of the diaphragm and sinuses are free. Heart and aorta, within age-related changes. EchoCG: FV 69\%. KDO $79 \mathrm{ml}$. CSR $24 \mathrm{ml}$. UO 55ml. Severe LVH with systolic overload. Ultrasound: false aneurysm of the subclavian artery, right. Doppler sonography: on both sides, the main blood flow is anti-hail. The amplitude is saved.

At 4 months after the injury, the patient complained of a feeling of pressure and pain in the supraclavicular region; the presence of education on the supraclavicular region on the right; numbness of the right upper limb; lack of movement of the fingers of the right cyst, general weakness. According to MSCT data from 03/16/2016, a pulsating volumetric lesion measuring $12 \times 10 \mathrm{~cm}$, motionless, painless, was identified (Fig. 3). Ultrasound: false aneurysm of the subclavian artery, right. Doppler sonography: on both sides, the blood flow is main, antegrade. The amplitude is saved.

When examined by an angiosurgeon, the diagnosis was formulated: false aneurysm of the subclavian artery, on the right.

On March 25, 2016, surgery was performed liquidation of a false aneurysm of the subclavian artery, on the right. At the first stage, endovascular occlusion of the subclavian artery was performed under intubation anesthesia. A skin incision of the supraclavicular region up to $15 \mathrm{~cm}$ long. on the right, above the aneurysm, the anterior wall of the pseudo-aneurysm is highlighted in a sharp and blunt way. Then, the wall of the false aneurysm was opened and about $300 \mathrm{~g}$ of the old blood clot was removed from it. Further, during the revision, a defect in the anterior wall of the subclavian artery with a diameter 
of up to $0.3 \mathrm{~cm}$ was established. The defect in the artery was restored with a lateral suture on the subclavian artery, with a Prolen 5/0 thread. The occluding balloon was removed from the subclavian artery. The seam is made, sealed. The aneurysm bed is drained through a separate skin incision. Dry hemostasis. A layered suture was applied to the wound. Aseptic adhesive has been produced (Figure 46).

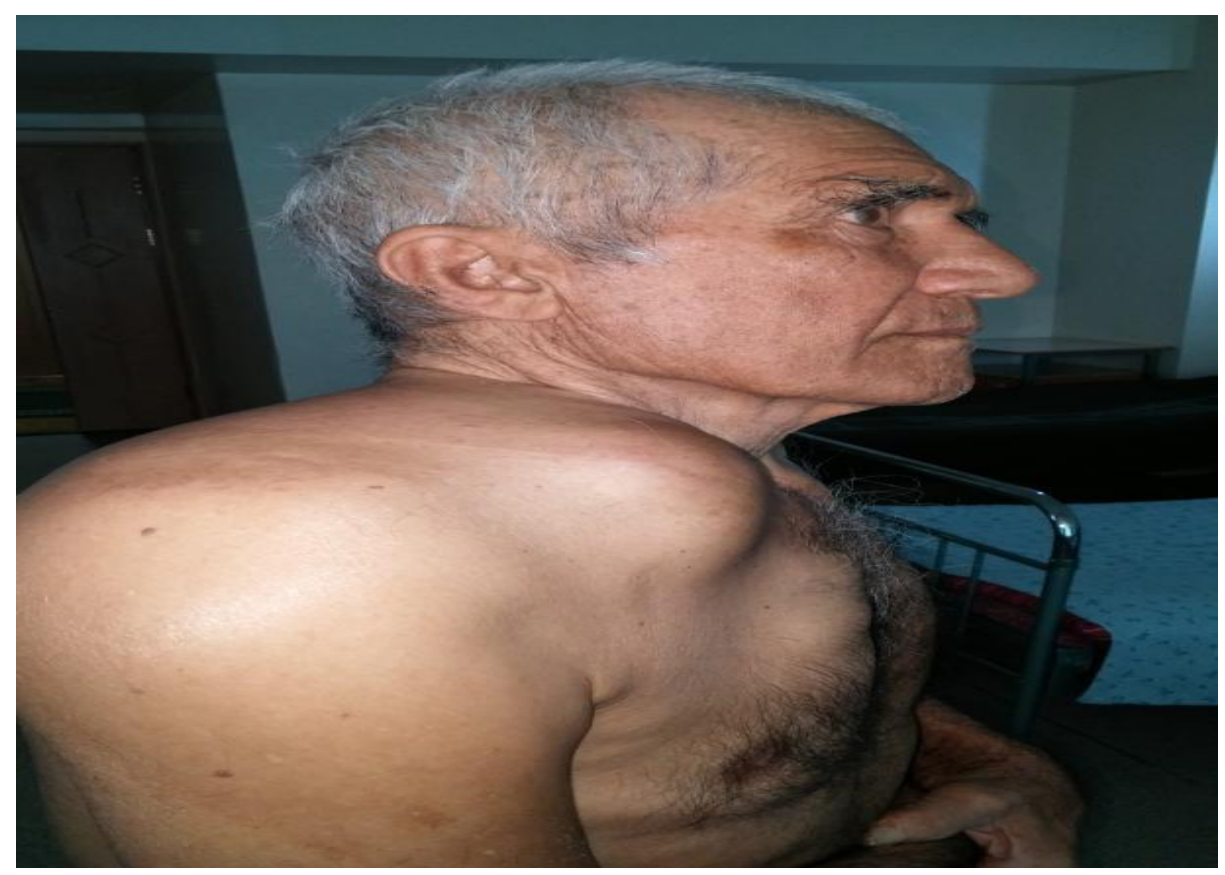

Fig.2. General view of the patient.

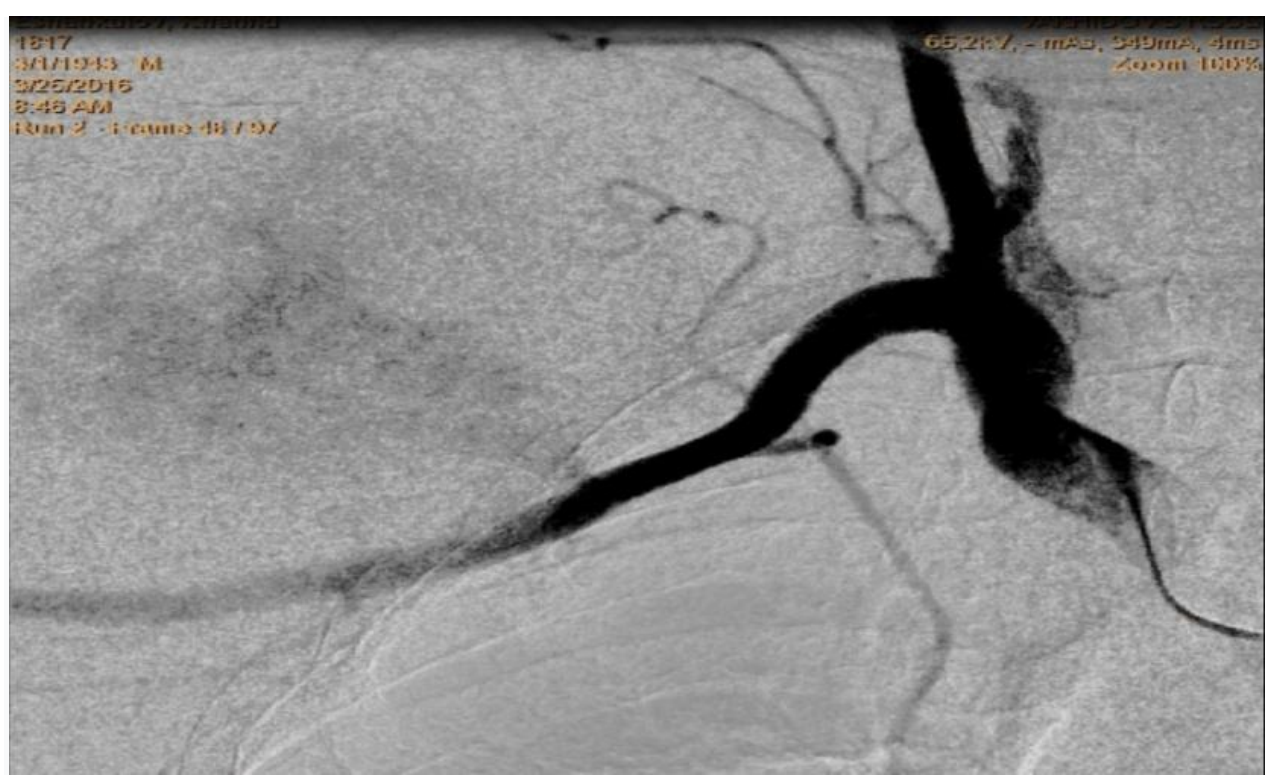

Fig. 3. MCST traumatic aneurysm of the subclavian artery, right. 
The American Journal of Medical Sciences and Pharmaceutical Research (ISSN - 2689-1026)

Published: August 29, 2020 | Pages: 106-112

IMPACT FACTOR

Doi: https://doi.org/10.37547/TAJMSPR/Volume02Issue08-17

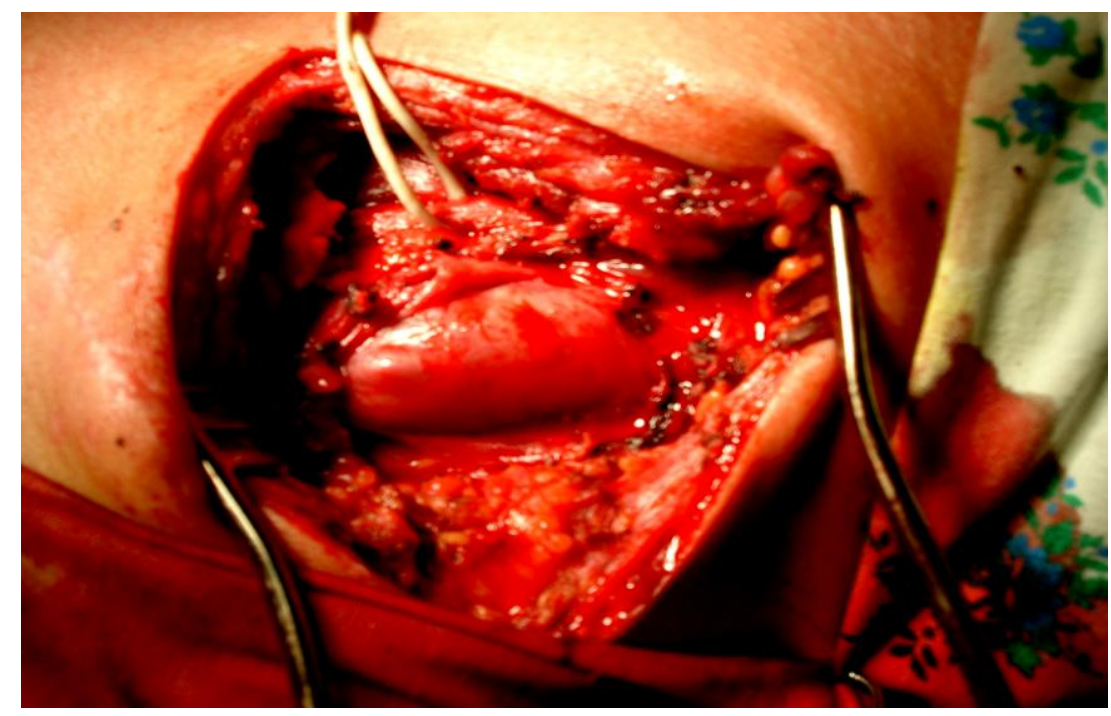

Fig. 4. Traumatic aneurysm of the subclavian artery, right.

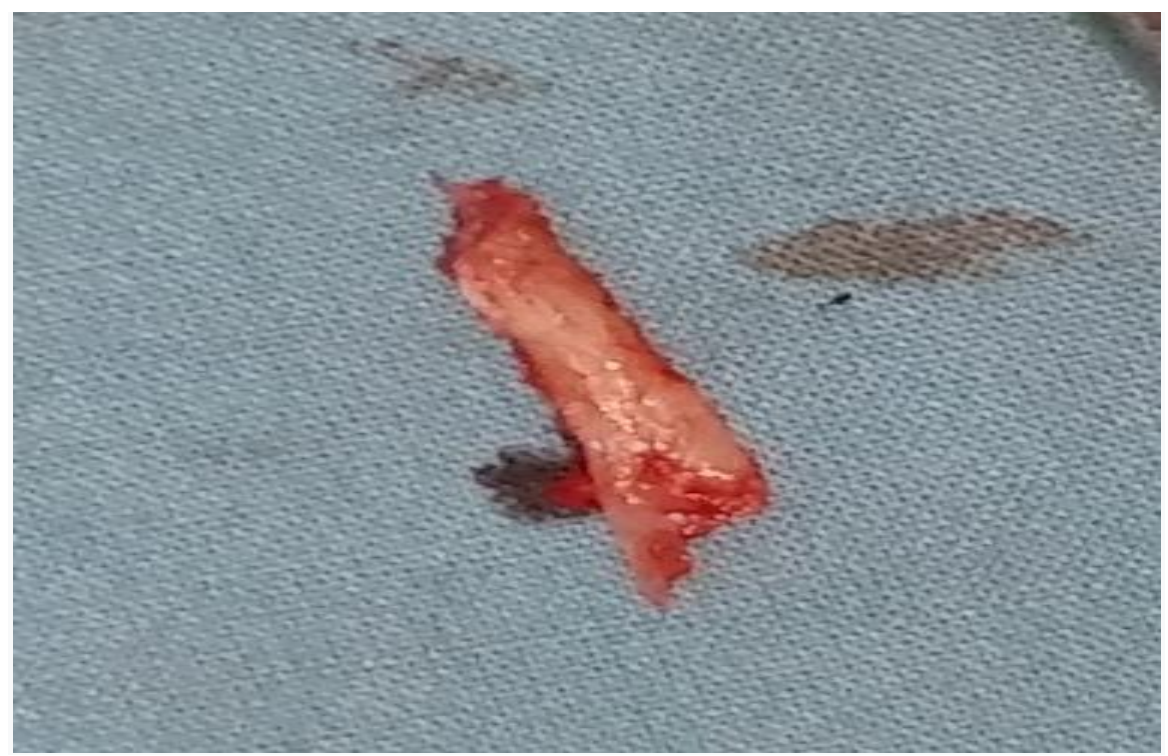

Fig.5.Fracture of the right clavicle. 


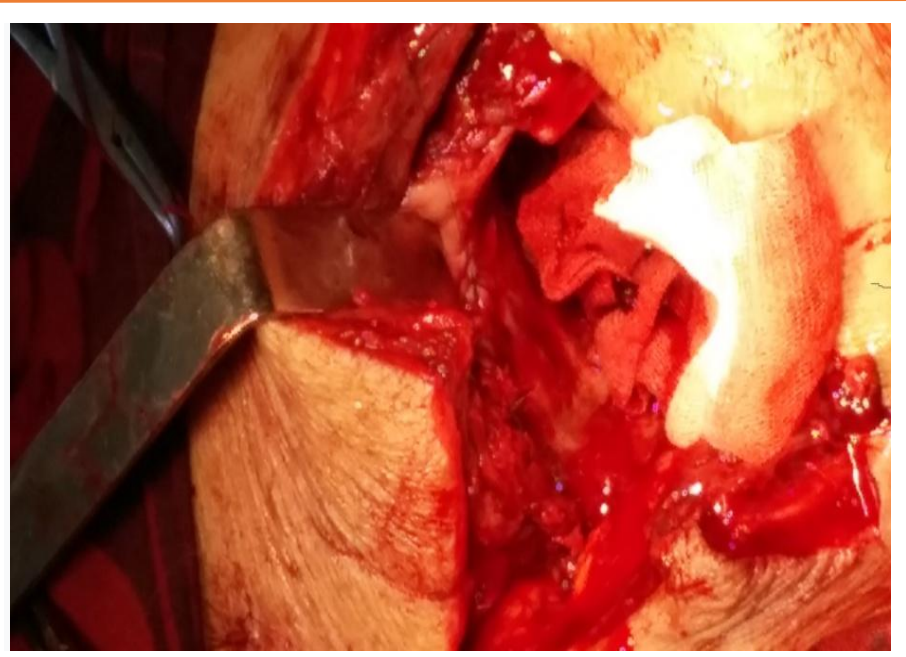

Fig. 6. Side seam in the right subclavian artery.

The postoperative period was without complications, the patient was discharged on the 7th day in a satisfactory condition. Examined a year later, he has no complaints, feels satisfactory.

The presented clinical observation demonstrates a rare case of a false aneurysm of the subclavian artery on the right after a fracture of the clavicle as a possible complication and successful treatment of this disease.

The authors declare no conflicts of interest.

\section{REFERENCES}

1. Yevstifeyev L.K.Travma magistral'nykh krovenosnykh sosudov mirnogo vremeni. Diss.... d-ra med.nauk.M.:1995;252.

2. Pryadko S.I., Semenov A.S., Morozov K.M. Anevrizmy perifericheskikh arteriydiagnostika taktika khirurgicheskogo lecheniya//Grudnayaserd.sosud.khirur.1997;2:189.

3. Khamrakulov Z.S., Zayniddin Norman ugli. Povrezhdeniya sosudov. Izdatel'stvo Ibn Siny. Tashkent.:1999;126.
4. Petrovskiy B.V., Milonov O.B. Khirurgiya anevrizm perifericheskikh sosudov.-M.: Meditsina, 1970;178

5. Pokrovskiy A.V., Zemskov N.N., Shor N.A. Povrezhdeniya magistral'nykh sosudov konechnostey.- Kiyev: Zdorov'ya, 1983; 210.

6. Gavrilenko A.V., Vakhrat'yan P.Ye., Kotov A.E., Alikin Ye.YU. Khirurgicheskoye lecheniye anevrizmy glubokoy bedrennoy arterii//Angiologiya i sosudistoy khirurgiya. 2013;2:139-144

7. Zayniddin Norman ugli., Bakhriddinov F.SH., Khusanov O.KH.Optimizatsiya tekhniki operatsii pri korrektsii posledstviy travmaticheskikh povrezhdeniy sosudov //Angiologiya i sosudistaya khirurgiya.2018;3:122-125.

8. Gumanenko Ye.K. Voyenno-polevaya khirurgiya. Spb Foliant: 2004; 464].

9. Rich N.M., Hobson R.W., Colins C.J. Vascular trauma secondary to diagnostic and therapentick procedures//Surgery.1974;Vol.78,6: 817828.

10. Mathen M. Carrick C. Fnnt Morrison et al. Modern managmtnt of traumatic subclavian artery injiures: a single 
Doi: https://doi.org/10.37547/TAJMSPR/Volume02Issue08-17

institions experience in the cloviution of endovascular repair. The American Joural jf surgery 2010.Jan: 199:1: 28-34. 